\title{
Hook Plate Applications in Type 3 Acromioclavicular
}

\section{Dislocations}

\author{
Sezai Özkan*, Cihan Adanaş \\ Department of Orthopedics and Traumatology, Van Yüzüncü Yll, Van, Turkey
}

\begin{abstract}
Acromioclavicular (AC) joint dislocations are caused by sports injuries fall from height or traffic accidents. While the treatment of Type 1 and Type 2 in AC dislocations is conservative, the treatment of Type 4, 5 and 6 is surgery. Treatment of type III dislocations is controversial. In this study, we aimed to investigate the functional results of patients who surgical treatment by using clavicle hook plate in Type III AC joint dislocations

21 patients $(18$ males, 3 females; mean age 34 years) with Type III AC joint dislocation who were admitted to our clinic between 2015-2017 were treated with clavicle hook plate. The surgical results of the patients at the 6th month were evaluated according to the Constant score.

Of the total 21 patient included in the study, $\mathrm{n}=18$ were male $(\% 86)$, and $\mathrm{n}=3$ were female $(\% 14)$. All patients were treated with clavicular hook plate. The average follow-up after treatment is 11 months. Functional results were obtained according to Constant scoring. There was no infection after surgery. Plaque irritation occurred in 2 patients and plaque was removed due to prolonged pain. 1 patient had recurrence.

Although conservative treatment of Type $3 \mathrm{AC}$ dislocations can provide adequate functional results in the long term, we believe that early results of the surgical treatment using clavicle hook plate is a reliable and effective method especially in the young age group.
\end{abstract}

Key Words: Acromioclavicular joints, joint dislocation, shoulder

\section{Introduction}

Acromioclavicular (AC) joint dislocations are caused by sports injuries, traffic accidents and fall from height. Approximately $9 \%$ of all shoulder injuries are AC joint injuries. Male / Female 5: 1 (1-2). Although conservative and surgical treatment options have been defined in the treatment of Type III AC joint dislocations, it has not been clarified which method is better $(3,4)$. Dias JJ et al reported that conservative treatment was better than surgical treatment (5). Recently, surgical techniques have been preferred with the development of surgical techniques $(6,7,8,9)$. Although many surgical techniques have been defined for the treatment of AC joint dislocations, there is no consensus on which method is better (10-11). Rockwood divided the AC joint dislocations into six groups. Type I and type II dislocations are treated by resting, ice, analgesic, immobilization and early joint exercises. The prognosis of Type I and Type II AC joint dislocations is good. Treatment of type III dislocations is controversial. Conservative treatment or surgical treatment options have been reported $(1,6,7,12,13,14)$. The treatment of type IV, V and VI dislocations is surgery. In 1982, Wolter designed clavicle hook plates. These plaques were modified in 2005, resulting in better results in the surgical treatment of AC dislocations (15). In this study, we aimed to investigate the functional results of patients who applied clavicle hook plate in Type III AC joint dislocations.

\section{Material and Method}

21 patients (18 males, 3 females; mean age 34 years) with Type III AC joint dislocation who were admitted to our clinic between 2015-2017 were treated with clavicle hook plate. Patients with chronic AC dislocation and clavicle fractures were excluded from the study. All patients were operated with general anaesthesia. The patients were given a semi-sitting position. The affected shoulder joint was prepared under sterile conditions. Surgery was started with a longitudinal incision on the AC joint. After the AC joint was opened and the disk was examined, the dislocated joint was reduced. The hook portion of the clavicle hook plate was placed with the back of the 
Table 1. Radiographic data of our patients

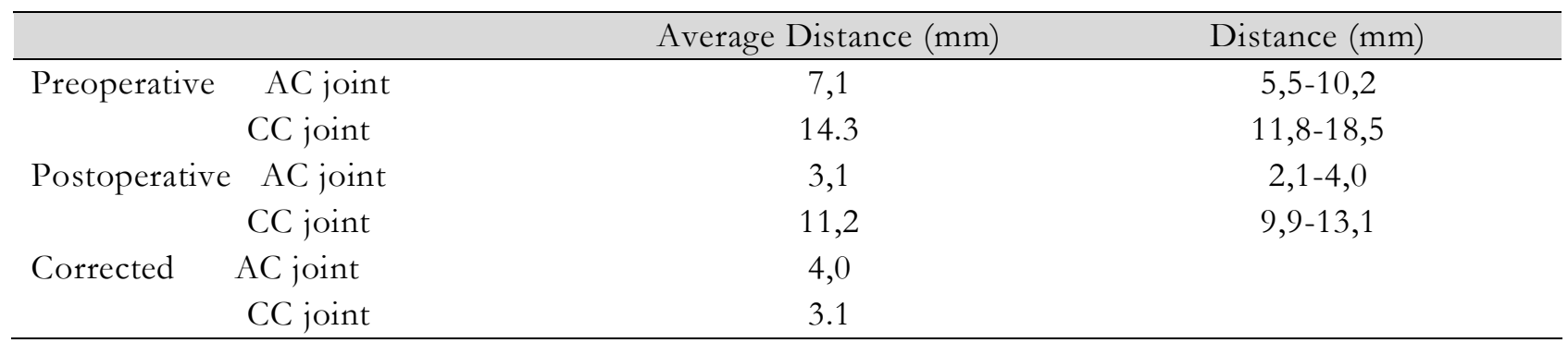

Table 2. Constant Score values of our patients

\begin{tabular}{lc}
\hline Constant score & Patients \\
\hline Very good & $10(\% 47)$ \\
Good & $8(\% 38)$ \\
Moderate & $2(\% 10)$ \\
Bad & $1(\% 5)$ \\
\hline
\end{tabular}

acromion. Joint fixation was achieved by placing 3 or 4 screws in the distal part of the plate. After surgery, shoulder bandage was used for 3 weeks. Panduler movements and climbing exercises were given to the shoulder joint on the 3rd postoperative day. After 3 weeks, active and passive shoulder joint movements were started. After 6 weeks, all shoulder movements were allowed. Surgical results of the patients were evaluated with the Constant score at 6 months. Constant scoring is performed according to pain, daily activity rate, flexion, abduction, internal rotation, external rotation and power rating of the $\mathrm{arm}$. The total score is $100 ; 15$ points of this pain, 20 points daily activity rate, 40 points movement degree, 25 points are given to muscle strength $(16,17)$. Radiological results of patients were evaluated according to preoperative and postoperative AC joint distance, coracoclavicular (CC) distance and presence of arthrosis in conventional radiographs.

\section{Results}

The mean age of 21 patients was 34 years (19-49 years). According to the causes of AC joint dislocation, 13 patients had occurred after sports injury, 4 patients after fall from height and 4 patients after traffic accident. Right shoulder was affected in 13 patients and left shoulder was affected in 8 patients. The mean operative time was 2 days (1-3 days). The mean follow-up period was 11 months (range, 8-13 months). No infection was observed in any patient after surgery. After the surgery, the plaque was removed in 2 of our patients because of irritation of the skin, and in 2 of our patients the clavicle hook was removed because of the long-term pain in the shoulder joint. Recurrence of AC joint dislocation was observed in one of the patients with clavicle hook plate removed. The patient did not want to be operated again. All of our patients returned to pre-operative social activities except for 2 patients. When the X-ray results were examined, the mean preoperative AC joint distance was corrected from $7.1 \mathrm{~mm}$ to $3.1 \mathrm{~mm}$. CC distance was reduced from $14.3 \mathrm{~mm}$ to $11.2 \mathrm{~mm}$ on average (Table 1).

According to the $x$-ray findings at 6 months postoperatively, 3 patients had arthritic changes in the AC joint. According to the results of Constant score of our patients after surgery, it was very good in 10 patients, good in 8 patients, moderate in 2 patients and bad in 1 patient. (Table 2).

\section{Discussion}

Treatment of Type I and Type II AC joint dislocations is conservative. There is consensus in the literature that the treatment of Type IV, Type $\mathrm{V}$ and Type VI AC joint dislocations is surgery. There is no consensus in the treatment of Type III dislocations. In many articles reported that there is no difference between the conservative treatment and the surgical treatment of Type III AC dislocations $(18,19,20,21)$. In some recent studies; There are authors who argue that the complete surgery reduction of the AC joint has better clinical and functional outcomes $(22,23)$. The success of surgical treatment depends on maintaining the anatomical reduction of the AC 


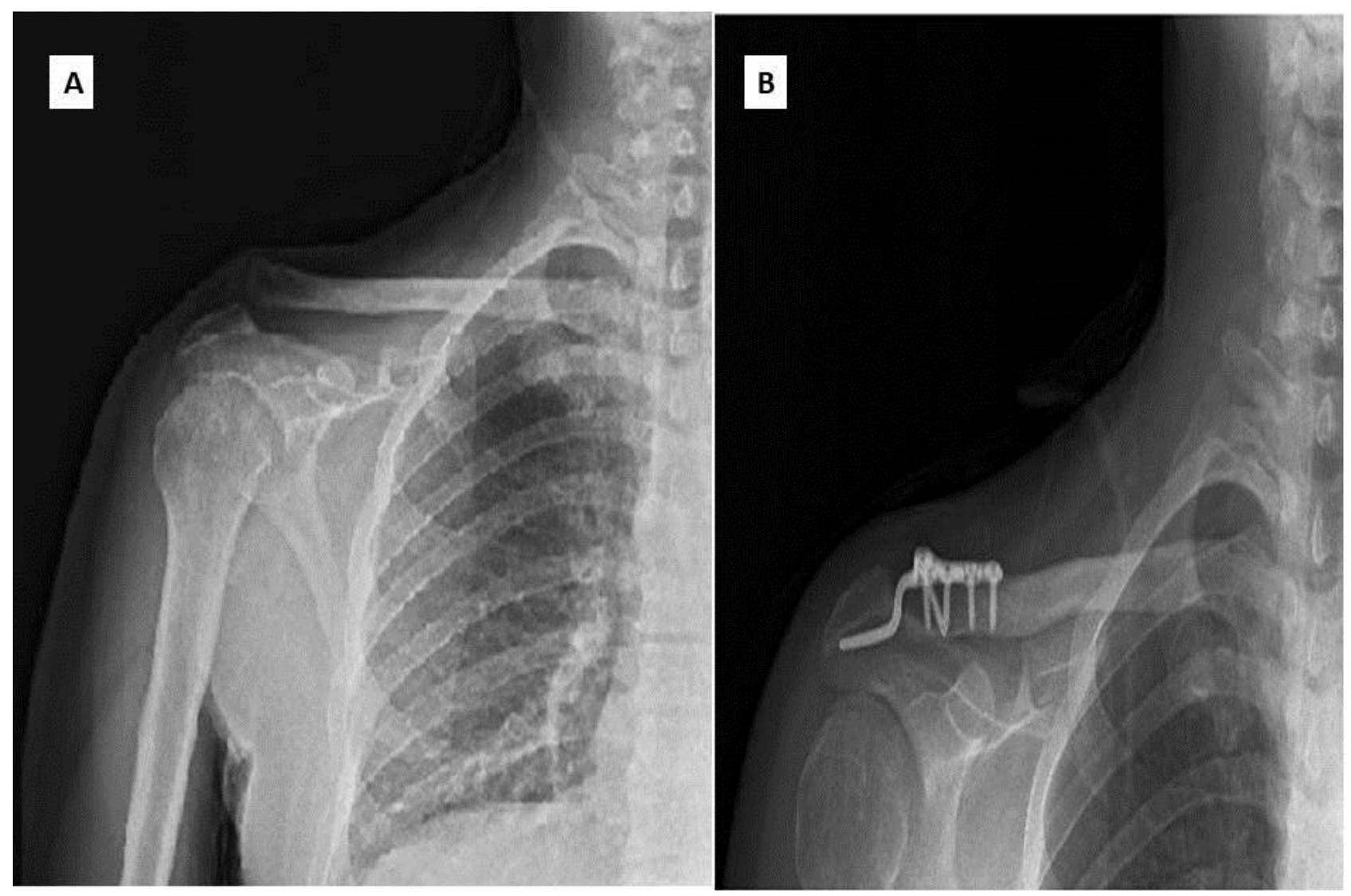

Fig.1. X-ray images of a patient preoperatively and postoperatively at the 6th month

joint and the improvement of the ligaments in the reduced position. Taft et al. reported that arthritic changes occurred in $\mathrm{AC}$ joint dislocations where anatomical reduction could not be achieved, but these changes had no effect on clinical and functional outcomes (24). Glick et al. reported that anatomical reduction was not a primary factor in functional outcomes, but $45 \%$ of osteoarthritis in the $\mathrm{AC}$ joint was caused by insufficient reduction (25). Surgical treatment is recommended in young patients, in heavy-duty workers, and in patients with severe AC joint dislocation (25). Since the patients in our study were in the young age group and mostly consisted of people who work in heavy jobs, surgical treatment was performed by using clavicle hook plate. In the treatment of AC joint dislocations, intraarticular fixation, CC (Coraco Clavicular) ligaments repair and $\mathrm{CC}$ screws fixation are the basic principles of treatment $(26,27)$. The use of clavicle hooks has become widespread in recent years. It has been reported that there are many advantages such as the use of both AC joint reduction and clavicle distal fractures, as well as allowing early rehabilitation $(28,29)$. The clavicle hook plates are not necessarily removed in the early period. Thus, sufficient time is provided for the joint capsule and ligaments to heal. Therefore, the risk of developing arthritis and stiffness in the shoulder joint is reduced. Other advantages of clavicle hook plates are easy application and short duration of operation $(29,30,31,32)$. In our study, the functional results of the patients treated with clavicle hook plate were quite satisfactory. Debates et al. reported that the mean Constat score 91.7 in patients who applied clavicle hook plate (31). The average Constant score of our study was 90.5 .

In 313 cases of Kienast et al. Infection rate after clavicle hook plaque was found $1.9 \%$ (32). In our study, none of the patients developed infection. The infection does not occur in any patient in our series. It might be attributed to the small number of patients included in the study. Long-term complications of using the clavicle hook plate include arthritic changes in the joint, osteolysis in the acromion, fractures in the plate, limitation of joint motion, and rotator cuff tears $(33,34,35,36)$. In our study, arthritic changes were observed in 3 patients and long-term pain was observed in 2 patients. The plaque was removed due to these complications. Recurrence was observed in one of these patients after removal of the clavicle hook plate. In a study by $\mathrm{Wu}$ et al. reported that longlasting pain occurred in the AC joint due to improper placement of the hook plate (28). We 
observed that two patients with long-term pain in the $\mathrm{AC}$ joint who had to remove the plaque were due to poor placement of the hook plate. It was observed that Ac joint reduction was easier, complications were less and patient satisfaction was higher when early surgical intervention was performed in AC joint dislocations. In a study by Weinstein et al. the results of late intervention of AC joint dislocations revealed worse surgical outcomes (36). In our study, all of our patients who underwent hook plaque were treated surgically in the early period.

In conclusion; Although adequate functional results can be obtained in the long term with conservative treatments in AC type III dislocations, we believe that early results of clavicle hook plate application is an effective and reliable method.

\section{References}

1. Monig SP, Burger C, Helling HJ, Prokop A, Rehm KE. Treatment of complete acromioclavicular dislocation: present indications and surgical technique with biodegradable cords. Int J Sports Med 1999; 20: 560-562.

2. Mazzocca AD, Arciero RA, Bicos J. Evaluation and treatment of acromioclavicular joint injuries. Am J Sports Med 2007; 35: 316-329.

3. Mardani-Kivi M, Mirbolook A, Salariyeh M, Hashemi-Motlagh K, Saheb-Ekhtiari $\mathrm{K}$. The comparison of Ethibond sutures and semitendinosus autograft in the surgical treatment of acromioclavicular dislocation. Acta Orthop Traumatol Turc 2013; 47: 307-310.

4. Bannister GC, Wallace WA, Stableforth PG, Hutson MA. The management of acute acromioclavicular dislocation. A randomised prospective controlled trial. J Bone Joint Surg Br 1989; 71: 848-850.

5. Dias JJ, Steingold RF, Richardson RA, Tesfayohannes B, Gregg PJ. The conservative treatment of acromioclavicular dislocation. Review after five years. J Bone Joint Surg $[\mathrm{Br}]$ 1987; 69: 719-722.

6. Pfahler M, Krodel A, Refior HJ. Surgical treatment of acromioclavicular dislocation. Arch Orthop Trauma Surg 1994; 113: 308311.
7. Schlegel TF, Burks RT, Marcus RL, Dunn HK. A prospective evaluation of untreated acute grade III acromioclavicular separations. Am J Sports Med 2001; 29: 699-703.

8. Bektașer B, Bozkurt M, Öçgüder A, Solak Ş, Oğuz T. Tip III akromiyoklaviküler eklem çıkıklarının modifiye Bosworth tekniği ile cerrahi tedavisi. Ulus Travma Acil Cerrahi Derg 2004; 10: 245-249.

9. faraj A.A, Ketzer B. The use of a hookplate in the management of acromioclavicular injuries. Report of ten cases. acta Orthop Belg 2001; 67: 448-451.

10. Collins DN. Disorders of the acromioclavicular joint. In: Rockwood CA Jr, Matsen FA 3rd, Wirth MA, Lippitt SB, editors. The shoulder. Philadelphia: Saunders (Elsevier) 2009; 453-526.

11. Simovitch R, Sanders B, Ozbaydar M, et al. Acromioclavicular joint injuries: diagnosis and management. J Am Acad Orthop Surg 2009; 17: 207-219.

12. Bannister GC, Wallace WA, Stableforth PG, Hutson MA. The management of acute acromioclavicular dislocation. A randomised prospective controlled trial. J Bone Joint Surg [Br] 1989; 71: 848-850.

13. Broos P, Stoffelen D, Van de Sijpe K, Fourneau I. Surgical management of complete Tossy III acromioclavicular joint dislocation with the Bosworth screw or the Wolter plate. A critical evaluation. Unfallchirurgie 1997; 23: 153-159.

14. Esenyel CZ, Oztürk K, Bülbül M, Ayanoğlu S, Ceylan HH. Coracoclavicular ligament repair and screw fixation in acromioclavicular dislocations. Acta Orthop Traumatol Turc 2010; 44: 194198.

15. Wolter d. C. Eggers, and W. Koch, Die operative Behandlung der akromioklavikulären luxation und der distalen klavikulafraktur oderpseudarthrose mit der acHakenplatte". Operat. Orthop. Traumatol 1989; 1: $145-$ 152.

16. Demirhan M, Akman Ş, Akalın Y. Omuz eklemi hastalıklarında preoperatif ve postaperatif skorlama. Acta Orthop Traumatol Turc 1993; 27: 129-131.

17. Constant C.R and Murley A.H.. A clinical method of functional assessment of the 
shoulder. Clin Orthop Relat Res 1987; 160-164.

18. Fremerey RW, Lobenhoffer P, Ramacker K, Gerich T, Skutek M, Bosch U. Acute acromioclavicular joint dislocation-operative or conservative therapy? Unfallchirurg 2001; 104: 294-299.

19. Dias JJ, Steingold RF, Richardson RA, Tesfayohannes B, Gregg PJ. The conservative treatment of acromioclavicular dislocation. Review after five years. J Bone Joint Surg [Br] 1987; 69: 719-722.

20. Galpin RD, Hawkins RJ, Grainger RW. A comparative analysis of operative versus nonoperative treatment of grade III acromioclavicular separations. Clin Orthop 1985; 150-155.

21. Rawes ML, Dias JJ. Long-term results of conservative treatment for acromioclavicular dislocation. J Bone Joint Surg [Br] 1996; 78: 410-412.

22. Pfahler M, Krodel A, Refior HJ. Surgical treatment of acromioclavicular dislocation. Arch Orthop Trauma Surg 1994; 113: 308 311.

23. Pavlik A, Csepai D, Hidas P. Surgical treatment of chronic acromioclavicular joint dislocation by modified WeaverDunn procedure. Knee Surg Sports Traumatol Arthrosc 2001; 9: 307-312.

24. Taft TN, Wilson FC, Oglesby JW. Dislocation of the acromioclavicular joint. An end-result study. J Bone Joint Surg [Am] 1987; 69: 1045-1051.

25. Glick JM, Milburn LJ, Haggerty JF, Nishimoto D. Dislocated acromioclavicular joint: follow-up study of 35 unreduced acromioclavicular dislocations. Am J Sports Med 1977; 5: 264-270.

26. Rockwood CA Jr. Injuries to the acromioclavicular joint. In: Rockwood CA Jr, Green DP, editors. Fractures in adults. Vol 1, 2nd ed. Philadelphia: JB Lippincott 1984; 860-910.

27. Zhu L, Yang HJ, Zhao WJ, Yang WM, Zhou H. Case-control study on endobutton plate or clavicular hook plate for the repair of acromioclavicular joint dislocations. Zhongguo Gu Shang 2012; 25: 120-123.

28. Wu JH, Liao QD, Chen G, Zhong D, Li $\mathrm{KH}, \mathrm{Li}$ RJ. Clavicular hook plate in the treatment of dislocation of acromioclavicular joint and fracture of distal clavicle. Zhong Nan Da Xue Xue Bao Yi Xue Ban 2006; 31: 595-598.

29. Tiren D, van Bemmel AJ, Swank DJ, van der Linden FM. Hook plate fixation of acute displaced lateral clavicle fractures: mid-term results and a brief literature overview. J Orthop Surg Res 2012; 7: 2.

30. Reška M, Konečný J, Kašpar M, Kábela M, Cierník J. Stabilisation of the dislocated acromioclavicular joint and lateral fractures of the clavicle using a hook plate. Rozhl Chir 2013; 92:143-150.

31. De Baets T, Truijen J, Driesen R, Pittevils T. The treatment of acromioclavicular joint dislocation Tossy grade III with a clavicle hook plate.Acta Orthop Belg 2004; 70: 515-519.

32. Kienast B, Thietje R, Queitsch C, Gille J, Schulz AP, Meiners J. Mid-term results after operative treatment of rockwood grade III-V acromioclavicular joint dislocations with an AC-hook-plate. Eur J Med Res 2011; 24: 52-56.

33. Hoffler CE, Karas SG. Transacromial erosion of a locked subacromial hook plate: case report and review of literature. J Shoulder Elbow Surg 2010; 19 12-15.

34. Nadarajah R, Mahaluxmivala J, Amin A, Goodier DW. Clavicular hook-plate: complications of retaining the implant. Injury 2005; 36: 681-683.

35. Weinstein DM, McCann PD, McIIveen SJ, Flatow EL, Bigliani LU. Surgical treatment of complete acromioclavicular dislocations. Am J Sports Med 1995; 23: 324-331.

36. Gumustas SA, Saglam F, Komur B, et al. Surgical treatment of type III acromioclavicular dislocation: Bosworth technique versus hook plating. North Clin Istanb 2017; 5: 334-340. 